\title{
Suicide in patients with motor neuron disease ${ }^{1}$
}

\author{
S. Bak ${ }^{2}$, E.N. Stenager ${ }^{3}$, E. Stenager ${ }^{2}$, J. Boldsen ${ }^{4}$ and T.A. Smith ${ }^{5}$ \\ ${ }^{2}$ Department of Neurology, Odense University Hospital, DK-5000 Odense C, ${ }^{3}$ Clinical Institute, \\ Department of Psychiatry, Odense University Hospital, ${ }^{4}$ Institute of Community Health, \\ Department of Social Medicine, Odense University, and ${ }^{5}$ Department of Neurophysiology, \\ Odense University Hospital, Odense, Denmark
}

Correspondence to: S. Bak at above address

\begin{abstract}
The aim of the present study was to assess, through an epidemiological study, whether suicide risk is increased in patients with motor neuron disease (MND). The study involved 116 patients with MND. In the study period 92 patients died, 47 males and 45 females. No patients committed suicide. The number of expected suicides was 0.27 for males and 0.12 for females, a total of 0.38. The difference between observed and expected suicides was not statistically significant for males and females.
\end{abstract}

Keywords: Motor neuron disease - Prognosis - Suicide

\section{INTRODUCTION}

Motor neuron disease (MND) is a progressive degenerative disease of the motor neuron system in adults. The major symptoms are muscle weakness, dysarthria, dysphagia, muscle wasting and fasciculations. Respiratory muscles are usually affected late in the disease. Depending on clinical signs three subtypes are recognized: amyotrophic lateral sclerosis (ALS), progressive bulbar palsy (PBP) and progressive muscular atrophy (PMA; Rowland, 1980; Tandan and Bradley, 1985; Li et al., 1990).

Previous Danish population surveys have shown average annual incidence rates of $0.8-1.4 / 100000 /$ year and prevalence rates of 2.5-3.1/100000 (Kristensen and Melgaard, 1977; Højer-Pedersen et al., 1989). This is in accordance with results from other countries (Tandan and Bradley, 1985; Tysnes et al, 1991; Swash and Schwartz, 1992). The mean age of onset is approximately 60 years of age (Kristensen and Melgaard, 1977; Rowland, 1980; Christensen et al., 1990). Men are affected more frequently than females with a male:female ratio of 1.2:1 to 1.9:1 (Kristensen and Melgaard, 1977; Højer-Pedersen et al., 1989; Li et al., 1990; Tysnes et al., 1991; The Scottish Motor Neuron Disease Research Group, 1992). Old age or early bulbar symptoms indicate poor prognosis and the overall median survival time is 23 months from

\footnotetext{
${ }^{1}$ The study was presented in a condensed form at the XVth World Congress of Neurology, Vancouver, Canada, 5-10 September 1993.
}

onset (Christensen et al., 1990). The most common cause of death is probably ventilatory failure (Rowland, 1980; Leone et al., 1987; Christensen et al., 1990).

The risk of suicide in patients with neurological diseases has been assessed in several investigations (Stenager and Stenager, 1992). Generally somatic diseases and depression constitute the greatest risk factors for suicide (Nielsen et al., 1990). The lifetime risk of suicide in persons who have suffered from depression is $15 \%$ (Sainsbury, 1986).

Among patients with multiple sclerosis (MS) depression and suicide are more frequent compared with the background population. During the course of the disease $40-50 \%$ of MS patients experience depression (E. Stenager et al., 1991; Stenager et al., 1992) and the cumulative lifetime risk of committing suicide is $1.95 \%$ (Stenager et al., 1992). Suicide is also a frequent cause of death in patients with spinal cord injury, particularly in young patients and patients with paraplegia (DeVivo et al., 1991; Carlifue and Gerhart, 1991). Increased suicide risk is described in patients with epilepsy (White et al., 1979; Barraclough, 1987) and Huntington's disease (Schoenfeld et al., 1984) but these investigations are encumbered with methodological problems (Stenager and Stenager, 1992). Cancer patients are also at increased risk of suicide, particularly patients with depression (Louhivuori and Hakama, 1979; Stensman and Sundqvist-Stensman, 1988; E.N. Stenager et al., 1991).

Behavioural Neurology • Vol 7 . 1994

181 
The course of MND is often characterized by rapid deterioration and severe disablement. Sense of hopelessness, depression and increased risk of suicide could be a comprehensible reaction to this serious disease. However, no studies concerning the suicide risk in MND exist. The aim of the present study was to assess, through an epidemiologic study, whether patients with MND are at an increased suicide risk.

\section{METHODS}

The study involved all patients with MND who were treated in the Neurological Department at Odense University Hospital in the period 1 April 1973 to 31 October 1991. The diagnosis of MND is assigned to patients with progressive muscular weakness, progressive muscular atrophy and muscle fasciculations in the spinal area (PMA) or bulbar area (PBP) and additional presence of pyramidal tract involvement (ALS). Finally, absence of sensory involvement and sphincter abnormalities is required. The classic electrophysiological diagnostic criterion is evidence of active denervation, normal sensory nerve conduction studies, normal motor conduction studies (unless compound muscle action potential amplitudes are very reduced) and evidence of reinnervation (Behnia and Kelly, 1991). Usually examination of three limbs or two limbs and bulbar muscles are required. We accepted examination of fewer muscles if quantitative examination was carried out. In 96 patients $(83 \%)$ electrophysiological examination was performed. Twenty-three patients fulfilled the classic electrodiagnostic criteria. Electrophysiological findings compatible with MND were found in 54 patients but they failed to fulfill the classic criteria mainly because the examination was incomplete. Ten patients had electrophysiological findings compatible with other neurologic diseases, most commonly polyneuropathy. In nine cases the electrophysiological examination was normal. The final diagnosis was based on a combination of clinical and electrophysiological signs. Patients with normal electrophysiological findings or signs suggestive of other diseases were included if the clinical course was compatible with MND.

The majority of MND patients in Funen County are admitted to the Neurological Department at Odense University Hospital first of all to establish the diagnosis. Funen County, which is representative of Denmark, has a population of 435000 . Probably $3-11 \%$ of Danish patients with MND, mainly old patients with bulbar symptoms, are diagnosed and treated at local hospitals (Kristensen and Melgaard, 1977; Christensen et al., 1990).

Since 1952 all deaths in Denmark are registered at a central registry and the cause of death recorded. All deaths not due to natural causes (i.e. accidents, crimes, suicide) are reported to the police and the County Medical Officer and following their examination, the cause of death is registered. A previous study has assessed a high reliability of Danish suicide statistics (Kolmos and Bach, 1987).

To assess the suicide risk in MND, the standard mortality ratio for suicide (the ratio of observed to expected numbers of suicide) was calculated with regard to age and sex. The ratio was adjusted to the patient series for the calender year at the start of observation, i.e. point of diagnosis. The two-sided exact test was calculated for statistically significant differences using Poisson distribution probabilities. The $5 \%$ level was considered significant.

The study was approved by the local ethical committee for the counties of Funen and Vejle.

\section{RESULTS}

In the investigation period 116 patients with MND were treated in the Neurological Department at Odense University Hospital. During this period 92 patients died, 47 males and 45 females. None of the patients committed suicide. The number of expected suicides was 0.27 for males and 0.12 for females, a total of 0.38 . The difference between observed and expected suicides was not statistically significant.

\section{DISCUSSION}

The study is based on a selected hospital sample which has the advantage that the diagnoses were reached by a neurologist and usually confirmed by electrophysiological examination. Because of the severity of the symptoms, practically all patients were referred to a neurologist, generally at the Neurological Department of Odense University Hospital, but some patients may have been treated at private neurological clinics or in local hospitals with a consultant neurologist.

Our study shows a similar suicide risk for patients with MND to that in the background population. Part of the explanation may be that depression is relatively infrequent in MND ranging from a few per cent (Peters et al., 1978; Schiffer and Babigian, 1984; Newrick and Langton-Hewes, 1984; David and Gillham, 1986) to $22 \%$ of the patients (Houpt and Gould, 1977; Gould, 1980). This is in contrast to the occurrence of depression in multiple sclerosis (E. Stenager et al., 1991; Stenager et al., 1992), spinal cord injury (DeVivo et al., 1991; Carlifue and Gerhart, 1991) and cancer (Breibart, 1990; E.N. Stenager 
et al., 1991). Pain is often a prominent feature in cancer. Cancer patients with pain are particularly exposed to depression and therefore at increased risk of suicide (Breibart, 1990).

The major symptoms in MND are limb weakness, dysphagia and dysarthria. Some patients experience cramps and diffuse pain in the neck, back and limbs but severe pain is uncommon (Rowland, 1980; Newrick and Langton-Hewer, 1984). This may partly explain the rare occurrence of depression and suicide in MND patients.

The patient's knowledge and ideas of the disease influence the psychological reaction to the diagnosis. In the general public cancer is usually regarded as a terminal illness and is often associated with intense pain and suffering (Breibart, 1990). This point of view can lead the cancer patient towards hopelessness, depression and perhaps suicide. In the same way patients with Huntington's disease are well aware of the prognosis of the disease and may also be at higher risk of suicide (Schoenfeld et al., 1984; Stenager and Stenager, 1992). MND is a disease which is unknown to the general public. Usually the newly diagnosed MND patient is ignorant of the prognosis of the disease which may give rise to hope of treatment and cure (Gould, 1980).

Finally, cognitive dysfunction seems to be present in MND, although it is often slight. Frontal lobe dysfunction as well as global cognitive impairment has been described (Gallassi et al., 1985; David and Gillham, 1986; Poloni et al., 1986; Iwasaki et al., 1990; Ludolph et al., 1992) and may affect emotional reactions to the disease, towards less dysphoria and depression (David and Gillham, 1986). Whether patients with frontal lobe dysfunction are less likely to commit suicide is however not yet clarified.

In conclusion, suicide is rare in MND and we suggest that rare occurrence of depression, absence of severe pain, poor knowledge of the prognosis, and cognitive dysfunction lessen the risk of suicide in MND.

\section{REFERENCES}

Barraclough BM (1987) The suicide rate of epilepsy. Acta Psychiatrica Scandinavica, 76, 339-345.

Behnia M and Kelly JJ (1991) Role of electromyography in amyotrophic lateral sclerosis. Muscle and Nerve, 14, 1236-1241.

Breibart W (1990) Cancer pain and suicide. In: Advances in Pain Research and Therapy, Vol.16. (Eds ?? Foley et al.), pp. 399-411. Raven Press, New York.

Carlifue SW and Gerhart KA (1991) Behavioral and demographic predictors of suicide after traumatic spinal cord injury. Archives of Physical Medicine and Rehabilitation, 72, 488-492.

Christensen PB, Højer-Pedersen E and Jensen NB (1990) Survival of patients with amyotrophic lateral sclerosis in 2 Danish counties. Neurology, 40, 600-604.

David AS and Gillham RA (1986) Neuropsychological study of motor neuron disease. Psychosomatics, 27, 441445.

DeVivo MJ, Black KJ, Richards JS and Stover SL (1991) Suicide following spinal cord injury. Paraplegia, 29, 620 621.

Gallassi R, Montagna P, Ciardulli C, Lorusso S, Mussuto $V$ and Stracciari A (1985) Cognitive impairment in motor neuron disease. Acta Neurologica Scandinavica, 71, 480484.

Gould BS (1980) Psychiatric aspects. In: The Diagnosis and Treatment of Amyotrophic Lateral Sclerosis (Ed. DW Mulder), pp. 157-167. Houghton Mifflin, Boston.

Højer-Pedersen E, Christensen PB and Jensen NB (1989) Incidence and prevalence of motor neurone disease in two Danish counties. Neuroepidemiology, 8, 151-159.

Houpt JL, Gould BS and Norris FH (1977) Psychological characteristics of patients with amyotrophic lateral sclerosis (ALS). Psychosomatic Medicine, 39, 299-302.

Iwasaki Y, Kinoshita M, Ikeda K, Takamiya $\mathrm{K}$ and Shiojima T (1990) Cognitive impairment in amyotrophic lateral sclerosis and its relation to motor disabilities. Acta Neurologica Scandinavica, 81, 141-143.

Kolmos L and Bach E (1987) Sources of error in registering suicide. Acta Psychiatrica Scandinavica, Suppl 336 (76), $22-43$.

Kristensen O and Melgaard B (1977) Motor neuron disease. Prognosis and epidemiology. Acta Neurologica Scandinavica, 56, 299-308.

Leone M, Chandra V and Schoenberg BS (1987) Motor neuron disease in the United States, 1971 and 1973-1978: patterns of mortality and associated conditions at the time of death. Neurology, 37, 1339-1343.

Li TM, Alberman E and Swash M (1990) Clinical features and associations of 560 cases of motor neuron disease. Journal of Neurology, Neurosurgery and Psychiatry, 53, 1043-1045.

Louhivuori KA and Hakama M (1979) Risk of suicide among cancer patients. American Journal of Epidemiology, 109, 59-65.

Ludolph AC, Langen KJ, Regard M, Herzog H, Kemper B, Kuwert T, Boettger IG and Feinendegen L (1992) Frontal lobe function in amyotrophic lateral sclerosis: a neuropsychologic and positron emission tomography study. Acta Neurologica Scandinavica, 85, 81-89.

Newrick PG and Langton-Hewer R (1984) Motor neuron disease: can we do better? A study of 42 patients. British Medical Journal, 289, 539-542.

Nielsen B, Wang AG and Bille-Brahe U (1990) Attempted suicide in Denmark IV. A five year follow up. Acta Psychiatrica Scandinavica, 81, 250-254.

Peters PK, Swenson WM and Mulder DW (1978) Is there a characteristic personality profile in amyotrophic lateral sclerosis? Archives of Neurology, 35, 321-322.

Poloni M, Capitani E, Mazzini L and Ceroni M (1986) Neuropsychological measures in amyotrophic lateral sclerosis and their relationship with CT scan-assessed cerebral atrophy. Acta Neurologica Scandinavica, 74, 257-260. 
Rowland LP (1980) Motor neuron diseases: the clinical syndromes. In: The Diagnosis and Treatment of Amyotrophic Lateral Sclerosis (Ed. DW Mulder), pp. 7-33. Houghton Mifflin, Boston.

Sainsbury P (1986) Depression, suicide and suicide attempts. In: Suicide (Ed. A Roy), pp. 73-88. Williams \& Wilkins, Baltimore.

Schiffer RB and Babigian HM (1984) Behavioral disorders in multiple sclerosis, temporal lobe epilepsy, and amyotrophic lateral sclerosis. Archives of Neurology, 41, 10671069.

Schoenfeld M, Myers RH, Cupples LA, Berkman B, Sax DS and Clark E (1984) Increased rate of suicide among patients with Huntington's disease. Journal of Neurology, Neurosurgery and Psychiatry, 47, 1283-1287.

Stenager E, Knudsen L and Jensen K (1991) Multiple sclerosis: the impact of physical impairment and cognitive dysfunction on social and sparetime activities. Psychotherapy and Psychosomatics, 56, 123-128.

Stenager EN and Stenager E (1992) Suicide and patients with neurologic diseases. Methodologic problems. Archives of Neurology, 49, 1296-1303.

Stenager EN, Bille-Brahe U and Jensen K (1991) Kræft og selvmord. En litteraturoversigt. Ugeskr. Lager, 153, 764768 .

Stenager EN, Stenager E, Koch-Henriksen N, BrønnumHansen $\mathrm{H}$, Hyllested $\mathrm{K}$, Jensen $\mathrm{K}$ and Bille-Brahe $\mathrm{U}$ (1992) Suicide and multiple sclerosis: an epidemiological investigation. Journal of Neurology, Neurosurgery and Psychiatry, 55, 542-545.

Stensman R and Sundqvist-Stensman UB (1988) Physical disease and disability among 416 suicide cases in Sweden. Scandinavian Journal of Social Medicine, 16, 149. 153

Swash M and Schwartz MS (1992) What do we really know about amyotrophic lateral sclerosis? Journal of Neurological Science, 113, 4-16.

Tandan R and Bradley WG (1985) Amyotrophic lateral sclerosis: Part 1. Clinical features, pathology, and ethical issues in management. Annals of Neurology, 18, 271-280.

The Scottish Motor Neuron Disease Research Group (1992) The Scottish motor neuron disease register: a prospective study of adult onset motor neuron disease in Scotland. Methodology, demography and clinical features of incident cases in 1989. Journal of Neurology, Neurosurgery and Psychiatry, 55, 536-541.

Tysnes OB, Vollset SE and Aarli JA (1991) Epidemiology of amyotrophic lateral sclerosis in Hordaland county, western Norway. Acta Neurologica Scandinavica, 83, 280-285.

White SJ, McLean AEM and Howland C (1979) Anticonvulsant drugs and cancer. Lancet, 2, 458-561.

(Received January 1994; accepted as revised 21 July 1994) 


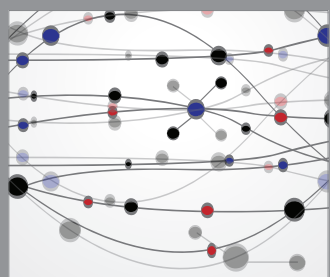

The Scientific World Journal
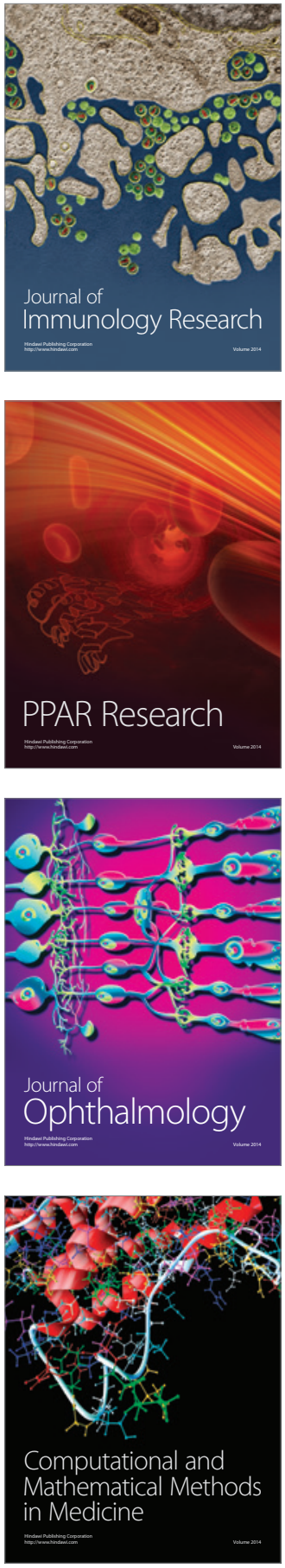

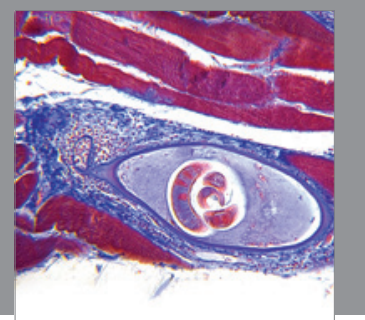

Gastroenterology

Research and Practice
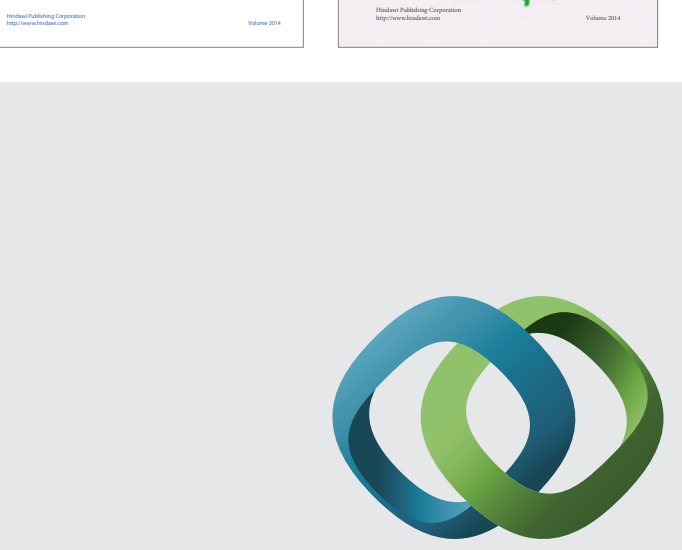

\section{Hindawi}

Submit your manuscripts at

http://www.hindawi.com
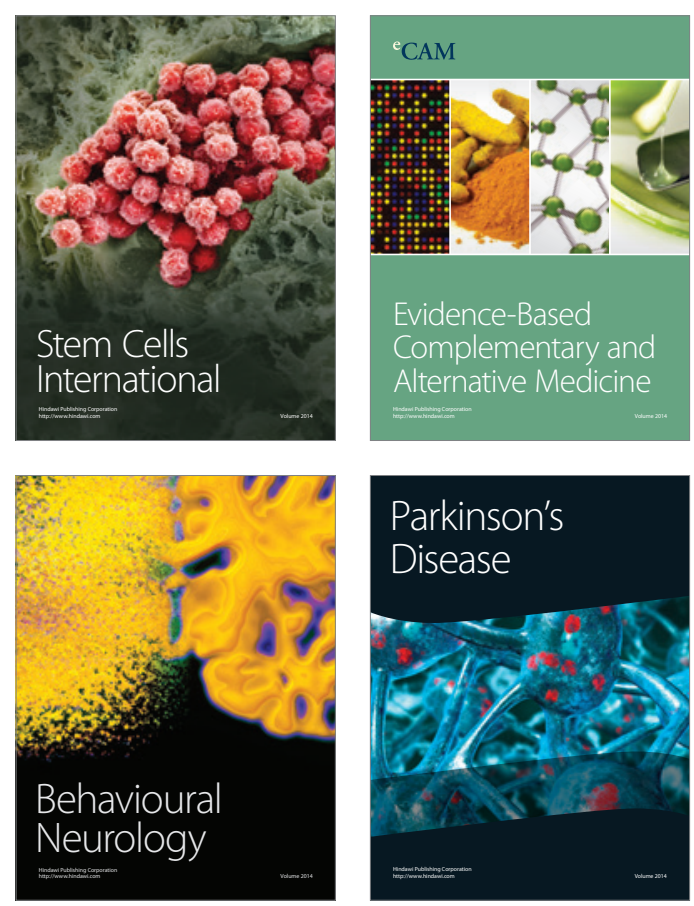

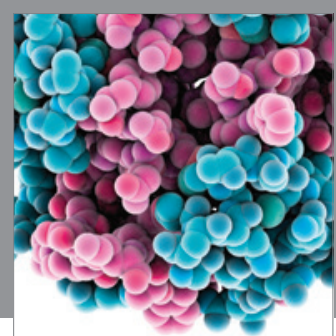

Journal of
Diabetes Research

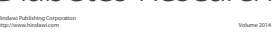

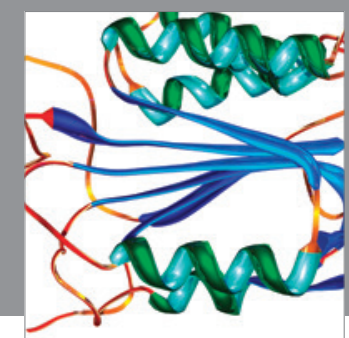

Disease Markers
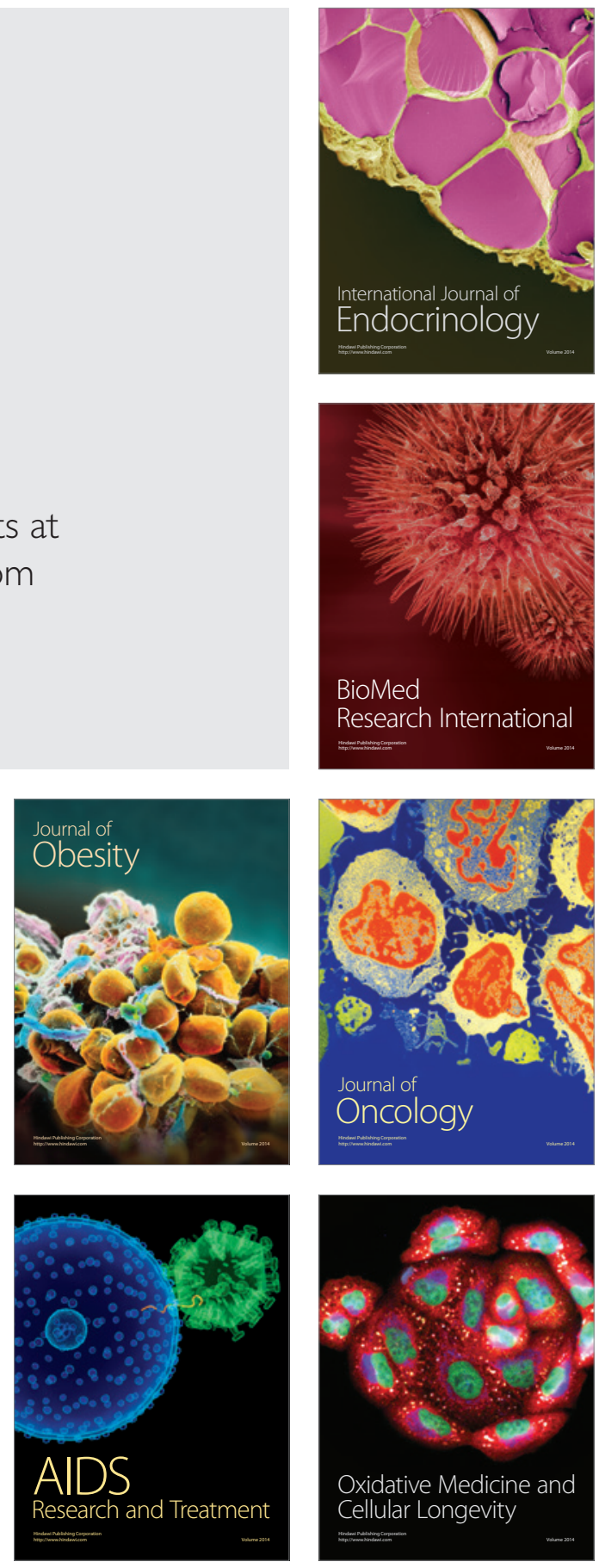